36 Sell DR, Monnier VM. Structure elucidation of a senescence cross-link from human extracellular matrix - implication of pentoses in the ageing process. $\mathcal{F} \mathrm{Biol} \mathrm{Chem} \mathrm{1989;}$ 264: 21597-602.

37 Sell DR, Monnier VM. End-stage renal disease and diabetes catalyse the formation of a pentose-derived cross-link catalyse the formation of a pentose-derived cross-link
from ageing human collagen. $\mathcal{f}$ Clin Invest 1990; 85: from agei.

38 Bailey AJ, Kent C. Non-enzymatic glycosylation of fibrous and basement membrane collagens. In: Baynes JS, Monnier VM, eds. The Maillard reaction in ageing, diabetes, and nutrition. New York: Alan R Liss, 1989: 109-22.

39 Andreassen TT, Seyer-Hansen K, Bailey AJ. Thermal stability, mechanical properties and reducible cross-links of rat tail tendon in experimental diabetes. Biochim Biophys Acta 1981; 677: 313-7.
40 Dyer DG, Blackledge JA, Thorpe SR, Baynes JW. Formation of pentosidine during nonenzymatic browning of proteins by glucose. F Biol Chem 1991; 266: 11654-60.

41 Albon J, Purslow PP, Duance VC, Easty DL, Karwatowski WSS. Mechanical compliance of the ageing human lamina cribrosa. Invest Ophthalmol Vis Sci 1994; 35 (suppl): 1645 .

42 Albon J, Purslow PP, Karwatowski WSS. Age-related compliance of the lamina cribrosa in human eyes. $f$ Biomechanics 1994; 27: 823 .

43 Lusky M, Morsman D, Weinreb RN. Effect of intraocular pressure on optic nerve head topography. Curr Opin Ophthalmol 1993; 4: 40-4.

44 Hernandez MR, Ye H. Glaucoma: changes in extracellular matrix in the optic nerve head. Ann Med 1993; 25: 309-15.

\title{
History of ophthalmology
}

\section{The discovery of accommodation}

The story of accommodation was pieced together over three centuries, by workers using only the most basic investigative tools. Knives, paper, muslin, candles, and blunt instruments are the only materials used in the experiments described below.

To set the scene, Aristotle and Galen had dissected animal and human eyes. From their drawings the basic anatomy of the globe and lens were common knowledge. Telescopes and the need to focus them had also been discovered. From this arises a first principle of optics: to vary focus, either the dioptric power or the length of an eyeball/telescope must change.

In 1619 , Scheiner published the results of an experiment proving that the eyes' dioptric power changes. Observing a near object through a paper screen with two tiny holes close together, the object is single. But focusing on any far object, the near object becomes double. Although Scheiner's conclusion was valid, it was disputed.

Some believed that the eyeballs focused by changing their length, elongating and shortening within the socket at need. This was refuted beautifully by Thomas Young in 1801. Young noted that a blunt object pressed on the posterior part of his eyeball produced a scotoma, which increased in size on increasing the pressure. Doing this during accommodation, Young saw no increase in scotoma, and concluded that the bar did not press more deeply on the back of the globe, therefore the eye could not have lengthened. Because he published his results in Philosophical Transactions, ophthalmologists took little notice.

Others accepted that the lens was involved in accommodation, but thought it changed its position within the globe. Many denied that accommodation took place at all. Haller, in 1743 , asserted that the pupillary constriction seen on converging for near objects in some way altered the depth of focus, and that no other explanation was required.

The controversy persisted. Donders, publishing his book on accommodation around 1860 , found it necessary to stress his own version of Scheiner's experiment. This involved holding a veil some inches from the eye, and an open book at greater distance. Either the texture of the veil, or the print could be seen accu- rately, but not both at once. 'Ergo, accommodation must exist,' reasoned Donders.

To appreciate the first proof that it resides in a change of form in the lens, an experiment performed in 1823 must be considered. Purkinje looked at the reflection of candlelight in someone's eyes and noted three reflected images. One was large, one small, and one inverted, and he correctly attributed them to reflection off the cornea, and the anterior and posterior surfaces of the lens.

This was initially applied to the diagnosis of cataract, but in 1849, Langenbeck realised that the images reflected from the lens could be used to investigate accommodation. Langenbeck published the right result in the wrong journal and was ignored. Thus it was left to Cramer to promulgate the following findings - that, holding a flame in front of an eye, the image reflected from the anterior lens surface becomes smaller when the subject accommodates. For the image to become smaller, the surface must increase in convexity. Therefore, the lens does change shape in accommodation. Helmholtz went a step further in noting that the image reflected from the posterior lens surface also changes, therefore that surface also increases in convexity.

The controversy lasted into the 1960 s, when textbooks quoted two rival theories of accommodation. Helmholtz believed that ciliary muscle contraction relaxed the zonule, whereupon the elastic lens became more curved. Tscherning believed that contraction tensed the zonule, which compressed the lens capsule to increase its curvature. Both theories depended on the lens being elastic, which was accepted by Donders in 1860, and confirmed in rabbits' eyes by Kikawa in 1963.

The acceptance of Helmholtz's theory over the next years ends the story, but the initial discoveries (that accommodation exists, involves the lens, and that the lens changes shape), made with the aid of such simple materials, make a very impressive tale of deductive reasoning.

F ROMAN

Adler FC. Physiology of the eye. St Louis: Mosby, 1965: 280-91. Davison H. The physiology of the eye. London: Churchill, 1949:

230-43.
Donders FC. Accommodation on the eye. Quoted in: Glendening L. Source book of medical history. New York: Henry Schuman, 1942. 